Original article

Section: Food Quality and Functionality

\title{
Phenolic Contents and Antioxidant Activity of Extracts of Selected Fresh and Dried Herbal Materials
}

\author{
Mariola Koztowska ${ }^{1 *} \odot$, Iwona Ścibisz ${ }^{2}$, Jarostaw L. Przybyt ${ }^{3} \odot$, Matgorzata Ziarno $^{2} \odot$, \\ Anna Żbikowska ${ }^{\circledR}$, Ewa Majewska ${ }^{1}{ }^{\circledR}$ \\ ${ }^{1}$ Department of Chemistry Institute of Food Science, Warsaw University of Life Sciences-SGGW, \\ Nowoursynowska 159C Str., 02-776 Warsaw, Poland \\ ${ }^{2}$ Department of Food Technology and Assessment, Institute of Food Science, Warsaw University of Life Sciences-SGGW, \\ Nowoursynowska 159C Str., 02-776 Warsaw, Poland \\ ${ }^{3}$ Department of Vegetable and Medicinal Plants, Institute of Horticulture Sciences, Warsaw University of Life Sciences-SGGW, \\ Nowoursynowska 159 Str., 02-776 Warsaw, Poland
}

Key words: coriander, lovage, tarragon, Indian borage, total phenolics, phenolic acids, flavonoids

Total phenolic content (TPC) and phenolic profiles of extracts of the aerial parts of coriander (Coriandrum sativum L.), lovage (Levisticum officinale Koch.), and tarragon (Artemisia dracunculus L.), and leaves of Indian borage (Plectranthus amboinicus) have been investigated. The extracts

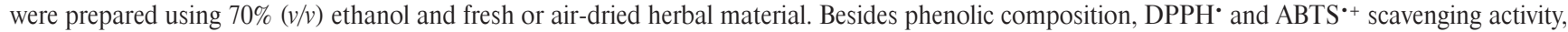
and ferric-reducing antioxidant power (FRAP) were determined. The extracts from dried herbal materials exhibited higher TPC and more potent antioxidant activity than those from fresh counterparts. The highest TPC ( $146.77 \mathrm{~g} \mathrm{GAE} / \mathrm{kg}$ extract) and antioxidant activity $(0.491,0.643$, and $0.396 \mathrm{~mol}$ TE/kg extract in DPPH, ABTS, and FRAP assays, respectively) were detected for the extract from dried leaves of Indian borage, while the lowest values were determined for the extract from fresh aerial parts of coriander. Five phenolic acids (rosmarinic, chlorogenic, caffeic, ferulic, and neochlorogenic acids) and four flavonoids ( $(+)$-catechin, rutin, hyperoside, and astragalin) were identified in the samples. Only caffeic acid was present in all extracts. Its content in the extracts of dried tarragon and Indian borage was lower than in those of the fresh material. A significant correlation was found between antioxidant activity and the content of phenolic acids. Rutin was found to be the major flavonoid in most extracts. Based on the present study results, the possibility of using the extracts obtained from both fresh and air-dried herbs as potential components for functional food formulation can be considered in the future.

\section{ABBREVIATIONS}

TPC: total phenolic content; FRAP: ferric-reducing antioxidant power; GAE: gallic acid equivalents; TE: Trolox equivalents.

\section{INTRODUCTION}

Plant materials, especially spices and herbs, have been used as food sources since the dawn of time, and their healing properties have been discovered with time as well. Nowadays, special attention is paid to a healthy lifestyle, diet as well as food products from organic farming where no chemicals are used. Due to this fact, a growing interest can be observed in plant material potency in the treatment and prevention of certain diseases. Spices and aromatic herbs are generally recognized by consumers as being safer for use in food manufacturing and processing, especially in dairy, meat, and bakery products, than synthetic food additives [Słowianek \& Leszczyńska, 2016; Ulewicz-Magulska $\&$ Wesolowski, 2019]. Both fresh and dried herbal materials are excellent additives to a variety of dishes, improving their appearance and enhancing their taste and aroma. Less desirable ingredients, such as salt, sugar or fat, can sometimes be partially replaced by such herbal materials [Tapsell et al., 2006]. Spices and herbs are cultivated in the open-field systems, quite often in home gardens as well as in pots or boxes on balconies and terraces. In this way, it is easy to obtain the raw herbal material of one's own without unnecessary expenditures. However, the quality of the raw herbal material is significantly influenced not only by the method of its cultivation, climatic and genetic factors, but also by the method of drying and storage, especially with regard to the biologically active compounds it contains, including e.g. phenolic compounds [Calín-Sánchez et al., 2020; Złotek et al., 2019]. Their presence in such a material may affect its antioxidant

\footnotetext{
* Corresponding Author:

Tel.: +48 22593 7614; Fax: +48 2259376 35;

E-mail: mariola_kozlowska@sggw.edu.pl (M. Kozłowska)
}

Submitted: 15 February 2021

Accepted: 14 June 2021

Published on-line: 20 July 2021 
properties, thus making it a viable ingredient for functional food formulations aimed to retard the process of lipid oxidation [Kozłowska et al., 2014, 2019].

Herbal plants are an extremely vast group of medicinal, spicy, and melliferous plants, and those rich in essential oils. They are used in food and pharmaceutical industries because of their strong antioxidant properties caused by the presence of phenolic compounds [Pabón-Baquero et al., 2018; Shahidi \& Ambigaipalan, 2015], which are accumulated in various plant parts, including fruits, leaves, seeds, and rhizomes, and can be classified into flavonoids, phenolic acids, stilbenes, lignans, and tannins. Plant phenolics positively influence human health, by inhibiting the oxidation of low density lipoproteins and the growth of bacteria, viruses, fungi, and by stimulating the growth of beneficial bacteria and activating or inhibiting enzymes that bind a specific receptor [Papuc et al., 2017; Shahidi \& Ambigaipalan, 2015]. Spices and herbs, but also beverages, fruits, and cereal products are important sources of plant phenolics in the human diet. The average phenolic intake in an adult population was estimated at approximately one gram of polyphenol per day [Zujko et al., 2012]. This may be important in reducing free radicals generation in a human body.

Drying fresh spices and herbs reduces their water content, and thus contributes to their shelf life extension by slowing or inhibiting the growth of microorganisms and affects the intensity of the ongoing biochemical and chemical reactions [Bourdoux et al., 2018; Calín-Sánchez et al., 2020; Roshanak et al., 2016]. This process can also lead to changes in the appearance and aroma of herbs due to the loss of volatiles or the formation of new ones as a result of oxidation and esterification reactions [Calín-Sánchez et al., 2020]. Some changes in the composition of bioactive components of plant material, such as phenolic compounds, ascorbic acid, and pigments, are also likely [Hossain et al., 2010; Roshanak et al., 2016]. Drying herbal material often requires finding the optimal conditions for a particular plant species, so as not to cause significant loss of color and taste, and to protect sensitive active ingredients [Calín-Sánchez et al., 2020]. In the case of mass production, the use of technical drying methods, such as convection oven, microwave, and freeze drying, is necessary. The selection of an appropriate drying method depends on the efficiency and the frequency of its use to attain optimal benefits without increasing costs and to assure the high quality of the dried material. However, the simplest, low-cost, and feasible for use at home method is natural drying in the shade, in a ventilated area or in the sunlight. Manually collected plants are dried by spreading them out in thin layers on trays or tying in bunches and hanging them with the leaves down [Hossain et al., 2010]. This type of drying, without auxiliary energy, either in the open-field or in special places is usually preferred for drying small quantities of plant material. Naturally air dried food products are also preferable by consumers who search for commodities made of natural substances or by natural processes. The naturally dried form is usually obtained from the whole aerial part of the fresh plant material, irrespective of the particular organs such as leaves, seeds or stems.
In the presented research, such herbs as coriander, tarragon, lovage, and Indian borage, were subjected to natural air drying, and the phenolic contents and antioxidant activity of extracts of the dried material and the fresh herbal material were compared. Although the content of phenolic compounds and their composition in these herb species had already been the topic of other publications [Al-Juhaimi \& Ghafoor, 2011; Bhatt et al., 2013; Spréa et al., 2020; Tajner-Czopek et al., 2020], they were often determined for individual organs of herbs, not for the whole aerial part, either fresh or naturally dried. Therefore, the aim of this study was to determine the antioxidant properties and the phenolic compound profile of the extracts of aerial parts of fresh herbal materials and material air-dried without sun exposure.

\section{MATERIALS AND METHODS}

\section{Reagents}

The Folin-Ciocalteu's phenol reagent, 2,2-diphenyl-1-picrylhydrazyl (DPPH) radical, gallic acid, 6-hydroxy-2,5,7,8-tetramethylchroman-2-carboxylic acid (Trolox), 2,2'-azinobis-(3-ethylbenzothiazoline-6-sulfonic acid) diammonium salt (ABTS), and 2,4,6-tri(2-pyridyl)-s-triazine (TPTZ) were purchased from Sigma-Aldrich (Poznań, Poland). High performance liquid chromatography (HPLC) standards were bought from Merck (Darmstadt, Germany) and ChromaDex® (Irvine, CA, USA). Other chemicals and solvents were obtained from Avantor Performance Materials (Gliwice, Poland). All of them were of analytical grade and were used as received, without further purification.

\section{Plant material}

The tested herbs included coriander (Coriandrum sativum L., family Apiaceae), lovage (Levisticum officinale Koch., family Apiaceae), tarragon (Artemisia dracunculus L., family Asteraceae), and Indian borage (Plectranthus amboinicus (Lour) Spreng; synonym: Coleus amboinicus, Coleus aromaticus, family Lamiaceae). All of them were purchased in pots at the beginning of July 2016 at the local market of Warsaw, Poland. Coriander, lovage, and tarragon came from a family business located in the heart of Kujawy, near Włocławek, Poland. The fresh aerial parts of these herbs, reaching approximately $25 \mathrm{~cm}$ in length, were cut off and divided into two batches. One (fresh) was cut into $1 \mathrm{~cm}$ long pieces and immediately used for extraction. The other batch of the fresh plant material was dried. For this purpose, several bunches of the tested herbs (approximately $1 \mathrm{~cm}$ in diameter) were prepared, which were subsequently hung upside down in a dry place without the sun exposure. The appropriate air flow and the average temperature of $25^{\circ} \mathrm{C}$ remained constant throughout the drying process. In the case of Indian borage, only fresh leaves and leaves dried without the sun exposure in appropriate air flow at the average temperature of $25^{\circ} \mathrm{C}$, on trays covered with cotton sheets, were used for extraction. The leaves on the trays were occasionally tossed. When herbs began to crumple easily between the fingers, they were crushed using mortar and pestle (particles passing through a $3 \mathrm{~mm}$ screen), packed, and stored in airtight containers until further use. The average moisture content of all dried herbal material was around $9.3 \pm 0.2 \mathrm{~g} / 100 \mathrm{~g}$. 


\section{Extract preparation}

The extraction of the fresh and dried herbal material was performed with $70 \%(v / v)$ ethanol based on the procedure reported by Kozłowska et al. [2015] with some modifications. Briefly, $20 \mathrm{~g}$ of each herbal material was transferred into the flasks containing $250 \mathrm{~mL}$ of aqueous ethanol. Then, the mixtures were stirred in a water bath for $10 \mathrm{~h}$ at $45^{\circ} \mathrm{C}$. The plant residues were filtered off through Whatman No. 1 paper filter, and ethanol was evaporated under vacuum on a rotary evaporator at $40^{\circ} \mathrm{C}$ (Rotavapor R-200, Büchi Labortechnik, Flavil, Switzerland). Next, the resultant extracts were freeze-dried (Alpha 1-4 LSC-plus, Osterode am Harz, Germany) and stored frozen until further use $\left(-20^{\circ} \mathrm{C}\right)$. The same extraction procedure was repeated for the new batch of the fresh and dried herbal material $(20 \mathrm{~g})$ using $70 \%(\mathrm{v} / \mathrm{v})$ aqueous ethanol $(250 \mathrm{~mL})$. The extraction yield was evaluated based on the mass balance.

\section{Total phenolic content (TPC)}

The content of total phenolics in freeze-dried herbal extracts was measured using a method given by Singleton \& Rossi [1965] with slight modification. A stock solution of the herbal extract was obtained by dissolving $1 \mathrm{mg}$ of each extract in $2 \mathrm{~mL}$ of $70 \%(\mathrm{v} / \mathrm{v})$ ethanol. Then, $1 \mathrm{~mL}$ of such prepared solution was diluted with distilled water $(9 \mathrm{~mL})$ and mixed with the Folin-Ciocalteu's phenol reagent $(0.5 \mathrm{~mL})$. After $3 \mathrm{~min}, 5 \mathrm{~mL}$ of saturated $\mathrm{Na}_{2} \mathrm{CO}_{3}$ solution was added. The mixture was made up to $50 \mathrm{~mL}$ with distilled water and stirred for about $1 \mathrm{~min}$. The sample was stored for $1 \mathrm{~h}$ at room temperature in the dark. Then the absorbance was recorded at $765 \mathrm{~nm}$ on a Shimadzu UV-1650 PC spectrophotometer (Kyoto, Japan) and used to calculate the TPC using gallic acid as a standard $(0.2-5 \mathrm{mg} / \mathrm{L})$. The results were expressed in $\mathrm{g}$ of gallic acid equivalents (GAE) per kg of extract.

\section{HPLC analysis}

The HPLC-DAD analysis of the phenolic compounds of the herbal extracts was performed using a Shimadzu Prominence chromatograph equipped with a SIL-20AC HT autosampler, an SPD-M20A photodiode array detector, and LCsolution 1.21 SP1 chromatography software (Shimadzu, Kyoto, Japan). Separation was performed using a C-18 column with a solid core and a porous outer layer (Kinetex $^{\mathrm{Tm}}, 100 \AA$, $2.6 \mu \mathrm{m}, 100 \times 4.60 \mathrm{~mm}$ i.d., Phenomenex, Torrance, CA, USA) and binary gradient of acetonitrile (ACN) and deionized water, acidified to $\mathrm{pH} 2$ with phosphoric acid (0 min-12.5\% ACN; $4.0 \mathrm{~min}-23 \% \mathrm{ACN}$; $6.0 \mathrm{~min}-50 \% \mathrm{ACN}$; $6.01 \mathrm{~min}-12.5 \% \mathrm{ACN} ; 10 \mathrm{~min}$ - stop) at flow rate $1.5 \mathrm{~mL} / \mathrm{min}$ and temperature $40^{\circ} \mathrm{C}$. Herbal extracts $(2 \mathrm{mg} / \mathrm{mL})$, before injection $(1 \mu \mathrm{L})$, were dissolved in $70 \%(v / v)$ ethanol and filtered with $0.20 \mu \mathrm{m}$ pore size PTFE Iso-Disc ${ }^{\mathrm{TM}}$ filters (Supelco Analytical $^{\mathrm{TM}}$, Bellefonte, PA, USA). Commercially available standards were prepared according to the ChromaDex's Tech Tip 0003: Reference Standard Recovery and Dilution [ChromaDex, 2016]. Six-point calibration curves were plotted according to the external standard method by correlating concentrations of the solutions with the obtained peak area. Parameters of method validation, such as linearity range $(\mathrm{mg} / \mathrm{mL})$, precision (expressed as coefficient of variation $\mathrm{CV}, \%$ ), limit of detection (LOD, $\mu \mathrm{g} / \mathrm{L}$ ), limit of quantitation (LOQ, $\mu \mathrm{g} / \mathrm{L})$, and recovery $(\%)$ were calculated according to International Conference on Harmonization ICH Q2 (R1) guidelines [2005] and their values are shown in Table 1. The signal-to-noise ratio approach was used to determine LOD (S/N of 3:1) and LOQ (S/N of 10:1). The compounds present in the extracts were identified by comparing their retention times and UV-VIS spectra (190-450 nm) with those of the standards, and quantified from the peak area according to the calibration curve equation of a respective standard.

\section{DPPH radical scavenging activity}

The antiradical activity of the herbal extracts was measured using the DPPH method according to Gow-Chin \& Hui-Yin [1995] with a slight modification. The herbal extract solutions were prepared by dissolving $3 \mathrm{mg}$ of each freeze-dried extract in $2 \mathrm{~mL}$ of $70 \%(v / v)$ ethanol. A $1 \mathrm{~mL}$ aliquot of freshly prepared $\mathrm{DPPH} \cdot$ methanolic solution $(0.3 \mathrm{mM})$ was

TABLE 1. Parameters of the HPLC method validation.

\begin{tabular}{|c|c|c|c|c|c|}
\hline Standard & Calibration equation & $R^{2}(n=6)$ & Linear range $(\mathrm{mg} / \mathrm{mL})$ & $\mathrm{LOD}(\mu \mathrm{g} / \mathrm{L})$ & LOQ $(\mu \mathrm{g} / \mathrm{L})$ \\
\hline $\begin{array}{l}\text { Neochlorogenic acid } \\
\text { (5-O-caffeoylquinic acid) }\end{array}$ & $y=1809.0 x+1539.8$ & 0.9996 & $0.39-392.00$ & 0.02 & 0.06 \\
\hline$(+)$-Catechin & $y=8216.4 x-6069.3$ & 0.9998 & $0.95-950.00$ & 0.01 & 0.36 \\
\hline $\begin{array}{l}\text { Chlorogenic acid } \\
\text { (3-O-caffeoylquinic acid) }\end{array}$ & $y=6517.4 x-12016.6$ & 0.9997 & $0.40-39.46$ & 0.21 & 0.70 \\
\hline $\begin{array}{l}\text { Caffeic acid } \\
\text { (3,4-dihydroxycinnamic acid) }\end{array}$ & $y=2592.9 x+379.6$ & 0.9996 & $1.00-998.40$ & 0.03 & 0.08 \\
\hline $\begin{array}{l}\text { Ferulic acid } \\
\text { (4-hydroxy-3-methoxycinnamic acid) }\end{array}$ & $y=2424.6 x-1856.9$ & 0.9995 & $0.40-99.68$ & 0.11 & 0.35 \\
\hline $\begin{array}{l}\text { Rutin } \\
\text { (quercetin 3-O-rutinoside) }\end{array}$ & $y=1434.0 x-5093.0$ & 0.9999 & $0.91-90.67$ & 0.07 & 0.25 \\
\hline $\begin{array}{l}\text { Hyperoside } \\
\text { (quercetin 3-O-galactoside) }\end{array}$ & $y=3435.5 x-6882.2$ & 0.9999 & $0.38-38.40$ & 0.04 & 0.12 \\
\hline $\begin{array}{l}\text { Astragalin } \\
\text { (kaempferol 3-O-glucoside) }\end{array}$ & $y=2104.5 x-2426.3$ & 0.9999 & $0.41-81.91$ & 0.33 & 1.10 \\
\hline Rosmarinic acid & $y=2017.9 x+1100.4$ & 0.9999 & $0.43-434.02$ & 0.03 & 0.09 \\
\hline
\end{tabular}


added to $3.8 \mathrm{~mL}$ of methanol and $0.2 \mathrm{~mL}$ of particular herbal extract. The samples were vortexed and incubated for $10 \mathrm{~min}$ at room temperature in the dark. Then, the absorbance was recorded using a Shimadzu UV-1650 PC spectrophotometer at $517 \mathrm{~nm}$. The results were expressed as mol Trolox equivalents (TE) per kg of extract. Trolox was used as a reference standard (linear range $8-40 \mu \mathrm{M}$ ).

\section{ABTS radical cation scavenging activity}

The radical scavenging activity of extracts was also analyzed using $\mathrm{ABTS}^{*+}$ according to the method proposed by Re et al. [1999]. First, the ABTS radical cations were produced by mixing $5 \mathrm{~mL}$ of $14 \mathrm{mM}$ ABTS solution with $5 \mathrm{~mL}$ of $4.9 \mathrm{mM}$ potassium persulfate. Next, the mixture was allowed to stand for $12-16 \mathrm{~h}$ in the dark at room temperature before use. For the analysis, the obtained solution was diluted with water to the final absorbance of $0.70 \pm 0.02$ at $734 \mathrm{~nm}$. Then, $4 \mathrm{~mL}$ of the ABTS ${ }^{\cdot+}$ working solution was mixed with $40 \mu \mathrm{L}$ of the herbal extract prepared by dissolving $(3 \mathrm{mg})$ in $70 \%(v / v)$ ethanol $(2 \mathrm{~mL})$. The mixture was vortexed and left to stand at room temperature in the dark. After 6 min, the absorbance of the samples was measured at $734 \mathrm{~nm}$ using a Shimadzu UV-1650 PC spectrophotometer. Trolox was used as a reference standard (linear range $0-20 \mu \mathrm{M})$. Results were expressed as mol Trolox equivalents (TE) per kg of extract.

\section{Ferric-reducing antioxidant power (FRAP)}

The ferric-reducing antioxidant power assay was performed according to Benzie \& Strain procedure [1996] with a minor modification. The FRAP reagent consisted of $10 \mathrm{mM}$ TPTZ solution in $40 \mathrm{mM} \mathrm{HCl}, 300 \mathrm{mM}$ acetate buffer (pH 3.6), and $20 \mathrm{mM} \mathrm{FeCl}_{3}$ solution in proportions of 1:10:1 $(v / v / v)$. The FRAP solution $(3 \mathrm{~mL})$ was used in the reaction with the herbal extract of an appropriate concentration $(1.5 \mathrm{mg} / \mathrm{mL})$. The reaction was carried out for $10 \mathrm{~min}$ at room temperature. Then, the absorbance of the samples was measured at $593 \mathrm{~nm}$ using a Shimadzu UV-1650 PC spectrophotometer. Results were reported as mol Trolox equivalents (TE) per $\mathrm{kg}$ of extract. A standard curve was prepared using Trolox in the concentration ranging from 80 to $500 \mu \mathrm{mol} / \mathrm{L}$.

\section{Statistical analysis}

All the analyses were performed at least in triplicate and the data were expressed as mean \pm standard deviation. The results were analyzed using the analysis of variance (ANOVA) with post-hoc Tukey's HSD test at the confidence level $\mathrm{p}<0.05$ (Statistica 13, Statsoft, Tulsa, OK, USA). The Pearson's test was used to find the correlation between the total phenolic content, antioxidant activity determined by DPPH, ABTS, and FRAP assays, and sums of phenolic acids and flavonoids from the HPLC analysis of the herbal extracts.

\section{RESULTS AND DISCUSSION}

\section{Extraction yield and total phenolic content}

The results presented in Table 2 show that the yield of the extraction process of the herbal material ranged from $1.69 \%$ to $31.89 \%$, with the lowest value found for the extracts obtained from the fresh leaves of Indian borage (P. amboinicus) and the highest one for dried aerial parts of tarragon and coriander. Generally, 7-15 times higher yields were observed for the extracts obtained from air-drying than from fresh herbal materials. However, Indian borage leaves, not only the fresh but also the dried ones, gave the aqueous ethanolic extracts with the lowest yield. Among the freeze-dried aqueous ethanolic extracts prepared from the fresh herbal material, the highest yield showed the one from coriander. The differences in yields of the extraction processes may stem from the water content in the initial material or from how the material was crushed or chopped.

The TPC of freeze-dried aqueous ethanolic extracts of the herbal material determined using the Folin-Ciocalteu method is presented in Table 2. The TPC of the extracts obtained from air-dried material was 1-1.8 times higher than that of the fresh herbal extracts. Among extracts made of both dried on air and fresh herbal materials, the extracts of Indian borage leaves had the highest TPC reaching 146.77 and $84.67 \mathrm{~g} \mathrm{GAE} / \mathrm{kg}$, respectively. In turn, the lowest TPC was determined for the coriander extracts obtained from fresh material. In the case of dried herbal materials, the tarragon extract had the lowest TPC. The total phenolic contents of tarragon and lovage $80 \%$ methanolic extracts

TABLE 2. Extraction yield and total phenolic contents (TPC) of the herbal extracts.

\begin{tabular}{|c|c|c|c|c|}
\hline Herbal material & & Latin name & Extraction yield (\%) & TPC (g GAE/kg extract) \\
\hline \multirow{4}{*}{ Fresh } & Coriander & Coriandrum sativum $\mathrm{L}$. & $3.35 \pm 0.39^{c}$ & $28.07 \pm 0.85^{\mathrm{f}}$ \\
\hline & Tarragon & Artemisia dracunculus L. & $2.06 \pm 0.25^{\mathrm{d}}$ & $32.91 \pm 0.68^{\mathrm{e}}$ \\
\hline & Lovage & Levisticum officinale Koch. & $2.83 \pm 0.31^{\mathrm{d}}$ & $51.04 \pm 0.72^{\mathrm{c}}$ \\
\hline & Indian borage & Plectranthus amboinicus (Lour) Spreng & $1.69 \pm 0.49^{\mathrm{e}}$ & $84.67 \pm 0.45^{\mathrm{b}}$ \\
\hline \multirow{4}{*}{ Dried } & Coriander & Coriandrum sativum $\mathrm{L}$. & $30.19 \pm 0.98^{\mathrm{a}}$ & $50.57 \pm 1.59^{c}$ \\
\hline & Tarragon & Artemisia dracunculus L. & $31.89 \pm 1.21^{\mathrm{a}}$ & $42.53 \pm 0.93^{\mathrm{d}}$ \\
\hline & Lovage & Levisticum officinale Koch. & $22.28 \pm 0.95^{\mathrm{b}}$ & $52.01 \pm 0.77^{\mathrm{c}}$ \\
\hline & Indian borage & Plectranthus amboinicus (Lour) Spreng & $21.97 \pm 1.05^{\mathrm{b}}$ & $146.77 \pm 2.05^{\mathrm{a}}$ \\
\hline
\end{tabular}

GAE, gallic acid equivalents. Means with different letters in the column are statistically different according to Tukey' test at $\mathrm{p}<0.05$. 
prepared using dried spices were determined by Słowianek \& Leszczyńska [2016]. The reported values, 41.2 and $17.8 \mathrm{mg}$ $\mathrm{GAE} / \mathrm{g}$, respectively, were related to those in our study for dried tarragon but lower for lovage extracts. Differences may be due to the use of a different type of solvent and, first of all, a different part of the herbal material in the extraction process. Ethanol, methanol, ethyl acetate, and acetone are commonly used for the extraction of phenolics from herbal materials [Sepahpour et al., 2018; Swamy et al., 2017]. The high polarity of these solvents can promote solubility of phenolic compounds and thus boost their extraction yield. According to Sepahpour et al. [2018], 80\% acetone was considered to be the best solvent for extracting TPC from turmeric, torch ginger, and lemon grass, whereas $80 \%$ ethanol was the most appropriate solvent for extracting phenolic compounds from curry leaf. In the case of herbs analyzed in our study, that aqueous ethanol was twice as effective as hot water in extracting total phenolic compounds from lovage [Spréa et al., 2020]. Similarly, Tajner-Czopek et al. [2020] noted a higher content of caffeic acid derivatives in aqueous ethanolic extracts of several herbs, including lovage and tarragon, compared to the water extracts. Furthermore, Swamy et al. [2017] reported that the TPC of a methanolic extract of Indian borage leaves was higher than that of the acetone and hexane extracts. However, Wangensteen et al. [2004] reported that ethyl acetate was a more preferred than diethyl ether and $n$-butanol solvent for phenolic extraction from coriander leaves and, also that this extract had higher TPC and better antioxidant properties than the extract from seeds. In turn, Al-Juhaimi \& Ghafoor [2011] showed that stems and leaves of coriander, parsley, and mint were good materials to produce extracts rich in phenolic compounds and effectively scavenging free radicals. They also reported that extracts of leaves from these herbs featured a higher TPC and higher antioxidant activity than the extracts from stems. In our study, the TPC of the aqueous ethanolic extracts obtained from dried coriander leaves and stems was higher compared to fresh coriander material extracts (Table 2) but lower to those reported by Harsha \& Anilakumar [2014]. The 70\% ethanol extract of the Coriandrum sativum prepared from leaves dried for three days in the shade containing $7 \%$ of water, evaluated by these authors, resulted in total phenolics at $133.74 \mu \mathrm{g}$ GAE/mg extract.

Changes in the content of biologically active constituents in herbs may be caused by the technological processes applied, such as drying and freezing. Herb drying inhibits microbial growth [Bourdoux et al., 2018] and leads to a stable, easily moveable product that is available throughout the year, but it may also change the content of phenolics [Hossain et al., 2010; Roshanak et al., 2016]. In our research, an increase was noticed in the TPC of extracts obtained from the dried materials compared to their fresh counterparts except from lovage (Table 2). In the case of this spice, drying did not cause statistically significant changes $(p \geq 0.05)$ in the content of these biologically active compounds. Contrary to the presented results, Tomsone \& Kruma [2014] revealed that fresh lovage leaves and stems had higher TPC than dried samples. Also Slimestad et al. [2020] reported that commercially available fresh herbs had a higher content of total phenolics compared to dried herbs offered as a ground product by local groceries. They explained that a lower TPC in dried material of the studied species might be a result of a long-term storage of dried products versus fresh herbs. In our study, the lower TPC of extracts of fresh plant material compared to air-dried samples may indicate that the enzymes present in fresh samples may have caused the degradation of these compounds. On the other hand, due to the low water activity in the dried samples, enzymes were inactivated, and high amounts of phenolic compounds remained in the extract. Moreover, during the drying process of herbs, the loss of moisture may be perceived as stress, which the plant responds to by activating the defense mechanism, including the production of phenolic compounds [Isah, 2019]. Similarly to the presented research, air-dried herbs from the Lamiaceae family had higher total phenolics and rosmarinic acid contents than fresh, freeze-dried and vacuum oven-dried their counterparts [Hossain et al., 2010]. Roshanak et al. [2016] also reported that dried green tea showed higher total phenolic and flavonoid contents than fresh material.

\section{HPLC analysis}

Five phenolic acids and four flavonoids were identified by HPLC in the extracts of herbal materials (Table 3). Caffeic acid was the phenolic acid present in all the tested extracts. Its content in the extracts obtained from the fresh herbal material, was higher than in the dried material with the exception of the coriander and lovage extracts. The coriander extract from the dried material had a higher content of caffeic acid than its counterpart obtained from the fresh material. The highest and the lowest contents of caffeic acid were determined in the aqueous ethanolic extracts of Indian borage and lovage, respectively, which is consistent with the literature data [Bhatt et al., 2013; Złotek et al., 2019]. In turn, Melo et al. [2005] found caffeic acid as the essential phenolic component of aqueous coriander extract fractions. Apart from caffeic acid, rosmarinic and chlorogenic acids were present in six out of the eight extracts tested. Ferulic acid was identified in five studied extracts and neochlorogenic acid only in two extracts obtained both from fresh and dried lovage. The highest content of rosmarinic acid was determined in the aqueous ethanolic extracts of Indian borage, while the extract from the fresh lovage showed the lowest content. The dried leaf extract of Indian borage was richer in rosmarinic acid and poorer in caffeic acid than its fresh counterparts The rosmarinic acid is a widespread phenolic acid found as dominant in many herbs of the Lamiaceae family [Slimestad et al., 2020; Yashin et al., 2017], which includes Indian borage [Bhatt et al., 2013]. In our study, drying the aerial part of tarragon and lovage, resulted in 23 and 2 times higher rosmarinic acid content respectively compared to the non-dried material. In turn, lovage drying caused the content of chlorogenic acid in the obtained extract to be almost 1.2 fold lower than its content in the extract from the fresh lovage. Chlorogenic acid was also the most predominant phenolic acid in the coriander extracts, especially, when dried material was used in the extraction process. The dried coriander herb also contained less caffeic acid $(0.714 \mathrm{~g} / \mathrm{kg}$ of extract) and ferulic acid $(0.006 \mathrm{~g} / \mathrm{kg}$ of extract). Previously, chlorogenic acid was determined as the major phenolic acid in lovage extracted with 


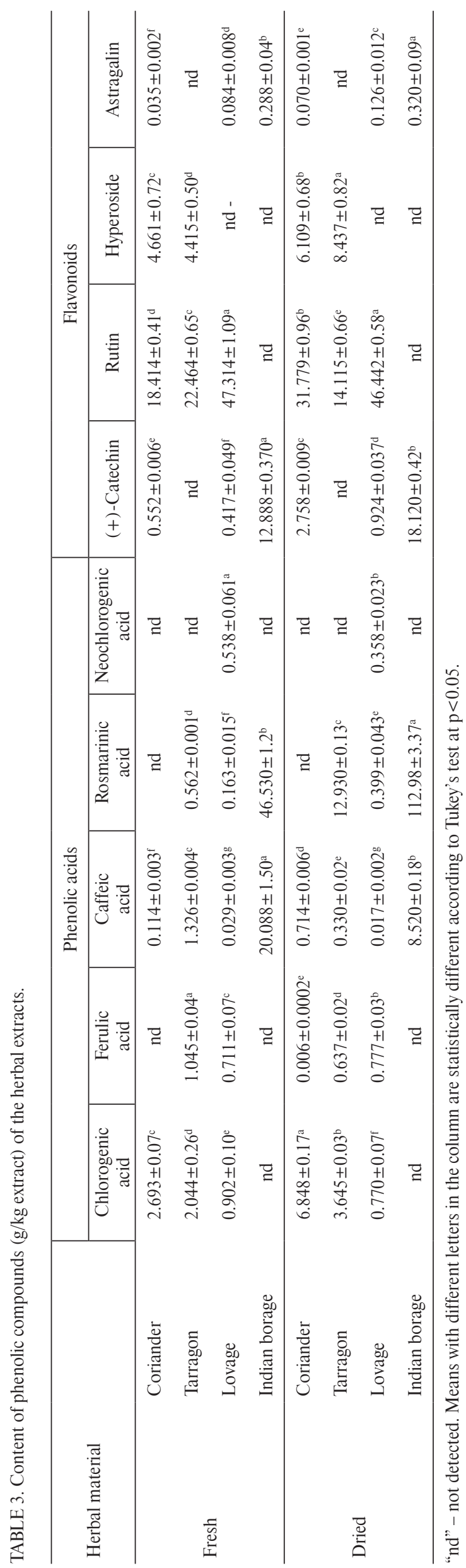

various solvents (aqueous ethanol, water, methanol) [Spréa et al., 2020; Tajner-Czopek et al., 2020; Ztotek et al., 2019] as well as commercially available fresh and dried coriander and tarragon [Slimestad et al., 2020]. In Rajeshwari \& Andullu [2011] studies, methanolic extracts of coriander seeds showed a higher content of chlorogenic and caffeic acids than their ethanolic counterparts. Phenolic acids tentatively identified in coriander leaves by high-performance liquid chromatography coupled to mass spectrometric were caffeic acid derivatives, including 5-feruloylquinic and 5-p-coumaroylquinic acids [Kaiser et al., 2013]. The mono- and dicaffeoyl quinic acid isomers as well as derivatives of sinapic, ferulic, and $p$-coumaric acids were also detected in lovage and tarragon [Spréa et al., 2020; Tajner-Czopek et al., 2020; Tvrda et al., 2019; Ztotek et al., 2019].

Four flavonoids, including astragalin (kaempferol 3-O-glucoside), hyperoside (quercetin 3-O-galactoside), rutin (quercetin 3-O-rutinoside), and (+)-catechin were identified in the extracts (Table 3). Astragalin was detected in small amounts in the coriander extracts from both fresh and dried material and in a slightly higher level in the lovage and Indian borage extracts. It is a natural flavonoid present in different medicinal plants, known for its various pharmacological properties such as anti-inflammatory, antioxidant, antidiabetic, and anticancer activities [Riaz et al., 2018]. Rutin was identified in the lovage, tarragon, and coriander extracts (Table 3). Among phenolic compounds, it was the predominant chemical compound detected in the lovage extracts prepared from both fresh and dried material. In this case, no significant differences $(p \geq 0.05)$ were found for the rutin content in both types of lovage extracts. The presence of rutin as the major flavonoid of the methanol lovage extracts was also confirmed by Tvrda et al. [2019] and Ztotek et al. [2019]. These authors also found other flavonoids, such as quercetin, cynarosid, apigenin, kaempferol, and/or their glycosides. TLC qualitative study indicated that $70 \%(v / v)$ ethanolic extract from tarragon contained rutin among flavonoids [Pirvu et al., 2014]. The presence of rutin in tarragon and coriander extracts was also reported by Slimestad et al. [2020].

The aqueous ethanolic extracts obtained from fresh and air-dried lovage, and dried coriander were richer in flavonoids than in phenolic acids (Figure 1). In turn, phenolic acids were the major compounds of the extracts from the fresh and air-dried leaves of Indian borage and from the air-dried aerial part of tarragon. It was also observed that the extracts from dried coriander and Indian borage contained more flavonoids and phenolic acids than those obtained from their fresh counterparts. On the other hand, extracts from the fresh tarragon had a slightly higher content of flavonoids compared to the extracts prepared from dried material. In turn, the content of phenolic acids in the extracts from air-dried tarragon was over 3 times higher than the one determined in the extracts from fresh raw material. However, a similar amount of flavonoids and phenolic acids was observed in the lovage extracts obtained from both dried and fresh herbal material. Among the fifteenth herbs analyzed by HPLC and mass spectrometry, the highest contents of flavonoids, measured as aglycones after acid hydrolysis, were found in lovage, mint, dill, and parsley [Justesen \& Knuthsen, 2001]. However, it should 


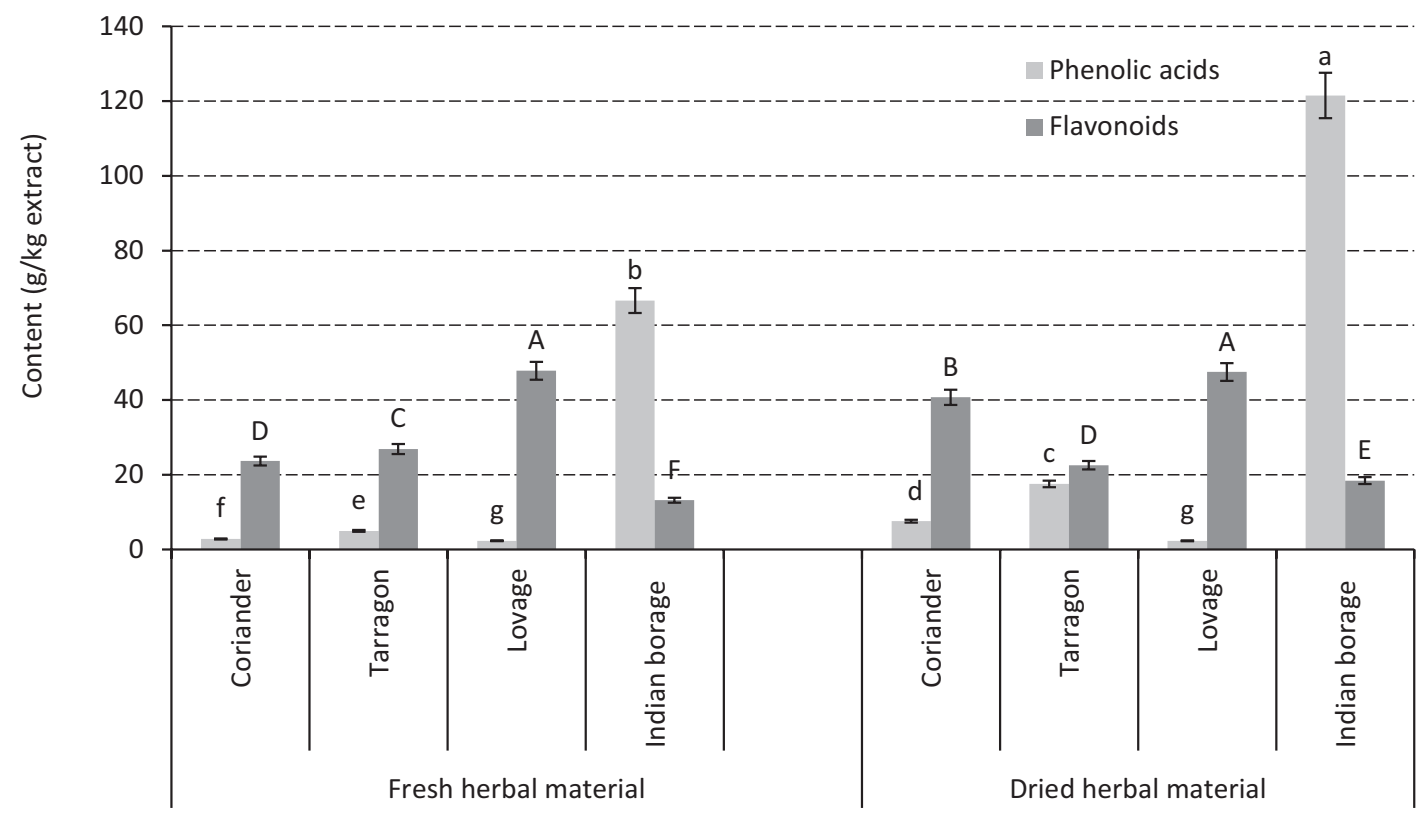

FIGURE 1. Phenolic acid and flavonoid contents of the herbal extracts. Significantly different values are marked with different letters above the bars (separately A-F and a-g) at $\mathrm{p}<0.05$.

be mentioned that the contents of both flavonoids and phenolic acids in herbal material may depend on plant cultivation conditions, harvest time as well as on genetic and ontogenetic factors. As an example, Karamać et al. [2020] found that the content ratio of flavonoids to phenolic acids in aerial parts of Camelina sativa changed significantly across the plant growth cycle. In turn, flavonoid content was lower in tarragon herb harvested at the beginning of September compared to the tarragon harvested at the beginning of July [Zawiślak \& Nurzyńska-Wierdak, 2014].

\section{Antioxidant activity}

The antioxidant properties of the herbal extracts are shown in Table 4. They were determined by DPPH, ABTS, and FRAP assays. All herbal extracts showed the ability to scavenge the $\mathrm{ABTS}^{\circ}+$ and $\mathrm{DPPH}^{\circ}$, and to reduce Fe(III). The results of antiradical activity determination indicated that the extracts from air-dried herbal material had significantly $(\mathrm{p}<0.05)$ higher both $\mathrm{DPPH}^{\bullet}$ and $\mathrm{ABTS}^{\bullet+}$ scavenging activities than those made of the fresh raw material. In the case of FRAP, only the dried tarragon aerial parts and Indian borage leaves yielded extracts with higher antioxidant activity than the fresh plants. FRAP of other dried herbal material extracts did not differ significantly $(\mathrm{p} \geq 0.05)$ from the corresponding extracts of fresh plants. The type of herb was also a factor differentiating antioxidant activity. The highest $\mathrm{DPPH}^{\bullet}$ and $\mathrm{ABTS}^{\cdot+}$ radical scavenging activity and FRAP was reported for the Indian borage leaf extracts. The antioxidant activity of other extracts obtained from fresh material decreased in the following order: Indian borage $>$ lovage $>$ coriander $>$ tarragon, regardless of the assay used for its determination. In the case of extracts obtained from air-dried plants, the order of their antioxidant activity changed as follows: Indian borage $>$ lovage $>$ tarragon $>$ coriander in the ABTS assay, Indian borage $>$ lovage $>$ tarragon $=$ coriander in the DPPH assay, and Indian borage $>$ lovage $=$ tarragon $>$ coriander in the FRAP assay.

The high antioxidant activity of Indian borage extracts compared to that of the other extracts examined may be due to the high content of rosmarinic acid in this herbal material (Table 3 and 4), which is a strong antioxidant and, among hydroxycinnamic acids, exhibited high scavenging activity due to the fact that its molecule contains four hydroxyl groups in structure [Chen \& Ho, 1997]. Our results are consistent with the earlier report showing that rosmarinic acid was predominantly responsible for the radical scavenging activity of Indian borage [Bhatt et al., 2013]. This acid significantly contributes to the antioxidant activity of many other plants of the Lamiaceae family, like sage,

TABLE 4. Antioxidant activity of the herbal extracts (mol TE/kg extract).

\begin{tabular}{cc|c|c|c}
\hline Herbal material & $\begin{array}{c}\text { DPPH } \\
\text { scavenging } \\
\text { activity }\end{array}$ & $\begin{array}{c}\text { ABTS }^{\bullet+} \\
\text { scavenging } \\
\text { activity }\end{array}$ & FRAP \\
\hline \multirow{4}{*}{ Fresh } & Coriander & $0.092 \pm 0.003^{\mathrm{f}}$ & $0.097 \pm 0.005^{\mathrm{f}}$ & $0.067 \pm 0.005^{\mathrm{d}}$ \\
& Tarragon & $0.037 \pm 0.002^{\mathrm{g}}$ & $0.051 \pm 0.005^{\mathrm{g}}$ & $0.042 \pm 0.010^{\mathrm{e}}$ \\
& $\begin{array}{l}\text { Lovage } \\
\text { Indian } \\
\text { borage }\end{array}$ & $0.159 \pm 0.001^{\mathrm{d}}$ & $0.204 \pm 0.004^{\mathrm{d}}$ & $0.109 \pm 0.003^{\mathrm{c}}$ \\
\hline \multirow{4}{*}{ Dried } & $0.288 \pm 0.006^{\mathrm{b}}$ & $0.435 \pm 0.009^{\mathrm{b}}$ & $0.205 \pm 0.007^{\mathrm{b}}$ \\
\hline & $\begin{array}{l}\text { Coriander } \\
\text { Tarragon }\end{array}$ & $0.129 \pm 0.005^{\mathrm{e}}$ & $0.137 \pm 0.004^{\mathrm{e}}$ & $0.059 \pm 0.006^{\mathrm{de}}$ \\
& $\begin{array}{l}\text { Lovage } \\
\text { Indian } \\
\text { borage }\end{array}$ & $0.156 \pm 0.003^{\mathrm{d}}$ & $0.151 \pm 0.003^{\mathrm{e}}$ & $0.092 \pm 0.005^{\mathrm{c}}$ \\
\hline
\end{tabular}

TE, Trolox equivalents; FRAP, ferric-reducing antioxidant power. Means with different letters in the column are statistically different according to Tukey's test at $\mathrm{p}<0.05$. 
TABLE 5. Coefficients of Pearson correlations between total phenolic content (TPC), antioxidant activity determined by DPPH, ABTS and FRAP assays, and sums of phenolic acids and flavonoids from HPLC analysis.

\begin{tabular}{l|c|c|c|c|c|c}
\hline & TPC & DPPH & ABTS & FRAP & $\begin{array}{c}\text { Phenolic } \\
\text { acids }\end{array}$ & Flavonoids \\
\hline DPPH & $0.978^{*}$ & & & & \\
ABTS & $0.976^{*}$ & $0.988^{*}$ & & & \\
FRAP & $0.983^{*}$ & $0.982^{*}$ & $0.979^{*}$ & & \\
$\begin{array}{l}\text { Phenolic } \\
\text { acids }\end{array}$ & $0.962^{*}$ & $0.939^{*}$ & $0.949^{*}$ & $0.968^{*}$ & \\
$\begin{array}{l}\text { Flavonoids } \\
\text { Flavon }\end{array}$ & -0.387 & -0.375 & -0.415 & -0.454 & -0.623 & \\
\hline
\end{tabular}

*Significant correlation at $\mathrm{p}<0.05$. FRAP, ferric-reducing antioxidant power.

thyme, oregano, basil, and marjoram [Yashin et al., 2017]. Studies on the antioxidant activity of Indian borage also showed that the extract from the stem was a more effective DPPH ${ }^{*}$ scavenger than the leaf extract [Bhatt et al., 2013; Kumaran \& Karunakaran, 2006]. In our study, also lovage extracts showed significant antioxidant activity, which corresponds to the report by Spréa et al. [2020] who demonstrated better results regarding antioxidant properties of aqueous ethanolic extracts obtained from the edible aerial parts of L. officinale (leaves and stems) in comparison with decoction extracts. It may be related to a higher concentration of phenolic compounds in hydroethanolic extracts that in decoction extracts. In turn, phenolic acids, especially caffeic acid, were considered as principal components responsible for the antioxidant activity of the aqueous coriander extract [Melo et al., 2005]. The antioxidant activity of caffeic acid is attributed to its chemical structure, including inter alia the presence of hydroxyl groups ortho-substituted in a benzene ring, and the existence of an unsaturated aliphatic chain, which increases the stability of the phenoxy radical by resonance [Chen \& Ho, 1997]. The total antioxidant capacity of herbal material may depend not only on the content of the phenolic compounds and their activity, but also on the presence of other antioxidants, such as vitamin $\mathrm{C}$, and possible synergistic or antagonistic interaction between phenolic antioxidants [Shahidi \& Ambigaipalan, 2015; Yashin et al., 2017]. Drying methods are also among the factors that may affect the changes in the content of biologically active compounds in plants, thus influencing their antioxidant potential [Calín-Sánchez et al., 2020].

The coefficients of Person correlation between antioxidant activity and the phenolic contents in the tested herbal extracts are shown in Table 5. A strong correlation was found between $\mathrm{DPPH}^{*}$ scavenging activity $(r=0.978)$, ABTS ${ }^{\cdot+}$ scavenging activity $(r=0.976)$, FRAP $(r=0.983)$, and TPC. A positive correlation was also found between results of all antioxidant activity assays and the content of phenolic acids. On the other hand, negative correlations were determined between the antioxidant activities of extracts and their flavonoid contents. In turn, the results of all antioxidant activity assays correlated significantly with each other $(r=0.976-0.983)$.
An excellent correlation between the total phenolics content and the \% inhibition of $\mathrm{DPPH}^{*}$ was previously shown for the coriander leaf-supplemented bread samples [Das et al., 2012]. Positive correlations between TPC of the seed and leaf coriander extracts obtained using different solvents and antiradical activity against $\mathrm{DPPH}^{\bullet}$ were also reported by Wangensteen et al. [2004]. A high linear correlation was also achieved between the results of the ABTS and DPPH assays for the ethanolic extracts from 23 different dried herbs and spices commercialized in Brazil [Mariutti et al., 2008]. This indicates that the average reactivity of the compounds present in different extracts towards both radicals could be considered similar. A strong correlation was observed by Kozłowska et al. [2016] between TPC and radical scavenging activity of seed oil samples from anise, coriander, caraway, white mustard, and nutmeg, and the methanolic extracts derived from these oils.

\section{CONCLUSIONS}

The presented research demonstrated the high total phenolic contents and potent antioxidant activity, measured as $\mathrm{DPPH}^{\bullet}$ and $\mathrm{ABTS}^{\cdot+}$ scavenging activity and FRAP of aqueous ethanolic extracts of coriander, lovage, and tarragon aerial parts, and Indian borage leaves. Generally, the higher total content of phenolic compounds and better antioxidant activity were found for the extracts prepared from air-dried herbal materials compared to those from fresh plants. Phenolic acid content in the herbal extracts significantly correlated with antioxidant activity. Caffeic acid was present in all extracts but its content was higher in the extracts from fresh than dried material for most plants. In turn, rosmarinic acid was the predominant phenolic acid in dried material in comparison to fresh counterparts. In brief, the drying of leaves and the aerial parts of herbal material did not cause any loss of phenolic compounds and did not reduce the antioxidant activity of their extracts. Therefore, extracts of both fresh and air-dried herbs can serve as potential components of functional food formulations.

\section{RESEARCH FUNDING}

This research did not receive any specific grant from funding agencies in the public, commercial, or not-for-profit sectors.

\section{CONFLICT OF INTEREST}

The authors declare no conflict of interest.

\section{ORCID IDs}

M. Kozłowska https://orcid.org/0000-0002-9252-3268 E. Majewska https://orcid.org/0000-0002-5910-1119 J.L. Przybył https://orcid.org/0000-0003-0959-184X I. Ścibisz https://orcid.org/0000-0003-1291-8962 M. Ziarno https://orcid.org/0000-0001-7445-6375 A. Żbikowska https://orcid.org/0000-0001-7013-4520 


\section{REFERENCES}

1. Al-Juhaimi, F., Ghafoor, K. (2011). Total phenols and antioxidant activities of leaf and stem extracts from coriander, mint and parsley grown in Saudi Arabia. Pakistan Journal of Botany, 43(4), 2235-2237.

2. Benzie, I.F.F., Strain, J.J. (1996). The ferric reducing ability of plasma (FRAP) as a measure of "Antioxidant Power". The FRAP assay. Analytical Biochemistry, 239(1), 70-76. https://doi.org/10.1006/abio.1996.0292

3. Bhatt, P., Joseph, G.S., Negi, P.S., Varadaraj, M.C. (2013). Chemical composition and nutraceutical potential of Indian borage (Plectranthus amboinicus) stem extract. Journal of Chemistry, 2013, art. no. 320329 .

\section{https://doi.org/10.1155/2013/320329}

4. Bourdoux, S., Rajkovic, A., De Sutter, S., Vermeulen, A., Spilimbergo, S., Zambon, A., Hofland, G., Uyttendaele, M., Devlieghere, F. (2018). Inactivation of Salmonella, Listeria monocytogenes and Escherichia coli O157:H7 inoculated on coriander by freezedrying and supercritical $\mathrm{CO}_{2}$ drying. Innovative Food Science and Emerging Technologies, 47, 180-186. https://doi.org/10.1016/j.ifset.2018.02.007

5. Calín-Sánchez, Á., Lipan, L., Cano-Lamadrid, M., Kharaghani, A., Masztalerz, K., Carbonell-Barrachina, Á.A., Figiel, A. (2020). Comparison of traditional and novel drying techniques and its effect on quality of fruits, vegetables and aromatic herbs. Foods, 9(9) art. no. 1261.

https://doi.org/10.3390/foods9091261

6. Chen, J.H., Ho, Ch-T. (1997). Antioxidant activities of caffeic acid and its related hydroxycinnamic acid compounds. Journal of Agricultural and Food Chemistry, 45(7), 2374-2378. https://doi.org/10.1021/jf970055t

7. ChromaDex, Standards, Tech Tips 0003: Reference Standard Recovery and Dilution. (2016). [https://standards.chromadex. com/Documents/Tech\%20Tips/techtip0003-recoverydilutionprocedures_nl_pw.pdf] (accessed: 1 February 2016).

8. Das, L., Raychaudhuri, U., Chakraborty, R. (2012). Supplementation of common white bread by coriander leaf powder. Food Science and Biotechnology, 21 (2), 425-433. https://doi.org/10.1007/s10068-012-0054-9

9. Gow-Chin, Y., Hui-Yin, C. (1995). Antioxidant activity of various tea extracts in relation to their antimutagenicity. Journal of Agricultural and Food Chemistry, 43(1) 27-32. https://doi.org/10.1021/jf00049a007

10. Harsha, S.N., Anilakumar, K.R. (2014). In vitro free radical scavenging and DNA damage protective property of Coriandrum sativum L. leaves extract. Journal of Food Science and Technology, 51(8), 1533-1539. https://doi.org/10.1007/s13197-012-0648-5

11. Hossain, M.B., Barry-Ryan, C., Martin-Diana, A.B., Brunton, N.P. (2010). Effect of drying method on the antioxidant capacity of six Lamiaceae herbs. Food Chemistry, 123, 85-91. https://doi.org/10.1016/j.foodchem.2010.04.003

12. International Conference on Harmonization ICHQ2 (R1) Guidelines. (2005). [https://database.ich.org/sites/default/files/ Q2_R1_Guideline.pdf] (accessed: 1 February 2016).

13. Isah, T. (2019). Stress and defense responses in plant secondary metabolites production. Biological Research, 52, art. no. 39. https://doi.org/10.1186/s40659-019-0246-3
14. Justesen, U., Knuthsen, P. (2001). Composition of flavonoids in fresh herbs and calculation of flavonoid intake by use of herbs in traditional Danish dishes. Food Chemistry, 73(2), 245-250. https://doi.org/10.1016/S0308-8146(01)00114-5

15. Kaiser, A., Kammerer, D.R., Carle, R. (2013). Impact of blanching on polyphenol stability and antioxidant capacity of innovative coriander (Coriandrum sativum L.) pastes. Food Chemistry, 140(1-2), 332-339.

https://doi.org/10.1016/j.foodchem.2013.02.077

16. Karamać, M., Gai, F., Peiretti, P.G. (2020). Effect of the growth stage of false flax (Camelina sativa $\mathrm{L}$.) on the phenolic compound content and antioxidant potential of the aerial part of the plant. Polish Journal of Food and Nutrition Sciences, 70(2), 189-198. https://doi.org/10.31883/pjfns/119719

17. Kozlowska, M, Zbikowska, M., Marciniak-Lukasiak, K., Kowalska, M. (2019). Herbal extracts incorporated into shortbread cookies: impact on color and fat quality of the cookies. Biomolecules, 9(12), art. no. 858 .

https://doi.org/10.3390/biom9120858

18. Kozłowska, M., Żbikowska, A., Gruczyńska, E., Żontała, K., Półtorak, A. (2014). Effects of spice extracts on lipid fraction oxidative stability of cookies investigated by DSC. Journal of Thermal Analysis and Calorimetry, 118, 1697-1705.

https://doi.org/10.1007/s10973-014-4058-y

19. Kozłowska, M., Laudy, A.E., Przybył, J., Ziarno, M., Majewska, E. (2015). Chemical composition and antibacterial activity of some medicinal plants from Lamiaceae family. Acta Poloniae Pharmaceutica - Drug Research, 72(4), 757-767.

20. Kozłowska, M., Gruczyńska, E., Ścibisz, I., Rudzińska, M. (2016). Fatty acids and sterols composition, and antioxidant activity of oils extracted from plant seeds. Food Chemistry, 213, $450-456$.

https://doi.org/10.1016/j.foodchem.2016.06.102

21. Kumaran, A., Karunakaran, R.J. (2006). Antioxidant and free radical scavenging activity of an aqueous extract of Coleus aromaticus. Food Chemistry, 97(1), 109-114. https://doi.org/10.1016/j.foodchem.2005.03.032

22. Mariutti, L.R.B., Barreto, G.P.M., Bragagnolo, N., Mercadante, A.Z. (2008). Free radical scavenging activity of ethanolic extracts from herbs and spices commercialized in Brazil. Brazilian Archives of Biology and Technology, 51 (6), 1225-1232. https://doi.org/10.1590/S1516-89132008000600018

23. Melo, E.A., Filho, J.M., Guerra, N.B. (2005). Characterization of antioxidant compounds in aqueous coriander extract (Coriandrum sativum L.). LWT - Food Science and Technology, 38(1), $15-19$.

https://doi.org/10.1016/j.Iwt.2004.03.011

24. Pabón-Baquero, L.C., Otálvaro-Álvarez, Á.M., Fernández, M.R.R., Chaparro-González, M.P. (2018). Plant extracts as antioxidant additives for food industry. In E. Shalaby (Editor). Antioxidants in Foods and Its Applications. IntechOpen, London, UK, pp. 87-115. https://doi.org/10.5772/intechopen.75444

25. Papuc, C., Goran, G.V., Predescu, C.N., Nicorescu, V., Stefan, G. (2017). Plant polyphenols as antioxidant and antibacterial agents for shelf-life extension of meat and meat products: classification, structures, sources, and action mechanisms. Comprehensive Reviews in Food Science and Food Safety, 16(6), 1243-1268. https://doi.org/10.1111/1541-4337.12298 
26. Pirvu, L., Hlevca, C., Nicu, I., Bubueanu, C. (2014). Comparative studies on analytical, antioxidant, and antimicrobial activities of a series of vegetal extracts prepared from eight plant species growing in Romania. Journal of Planar Chromatography, 27(5), 346-356.

https://doi.org/10.1556/JPC.27.2014.5.4

27. Rajeshwari, C.U., Andullu, B. (2011). Isolation and simultaneous detection of flavonoids in the methanolic and ethanolic extracts of Coriandrum sativum L. seeds by RP-HPLC. Pakistan Journal of Food Science, 21(1-4), 13-21.

28. Re, R., Pellegrini, N., Proteggente, A., Pannala, A., Yang, M., Rice-Evans, C. (1999). Antioxidant activity applying an improved ABTS radical cation decolorization assay. Free Radical Biology and Medicine, 26(9-10), 1231-1237.

https://doi.org/10.1016/S0891-5849(98)00315-3

29. Riaz, A., Rasul, A., Hussain, G., Zahoor, M.K., Jabeen, F., Subhani, Z., Younis, T., Ali, M., Sarfraz, I., Selamoglu, Z. (2018). Astragalin: a bioactive phytochemical with potential therapeutic activities. Advances in Pharmacological Sciences, 2018, art. no. 9794625.

\section{https://doi.org/10.1155/2018/9794625}

30. Roshanak, S., Rahimmalek, M., Goli, S.A.H. (2016). Evaluation of seven different drying treatments in respect to total flavonoid, phenolic, vitamin $\mathrm{C}$ content, chlorophyll, antioxidant activity and color of green tea (Camellia sinensis or C. assamica) leaves. Journal of Food Science and Technology, 53(1), 721-729. https://doi.org/10.1007/s13197-015-2030-x

31. Sepahpour, S., Selamat, J., Manap, M.Y.A., Khatib, A., Razis, A.F.A. (2018). Comparative analysis of chemical composition, antioxidant activity and quantitative characterization of some phenolic compounds in selected herbs and spices in different solvent extraction systems. Molecules, 23(2), art. no. 402.

https://doi.org/10.3390/molecules23020402

32. Shahidi, F., Ambigaipalan, P. (2015). Phenolics and polyphenolics in foods, beverages and spices: Antioxidant activity and health effects - A review. Journal of Functional Foods, 18(Part B), 820-897.

https://doi.org/10.1016/j.jff.2015.06.018

33. Singleton, V.L., Rossi, J.A. (1965). Colorimetry of total phenolics with phosphomolybdic-phosphotungstic acid reagents. American Journal of Enology and Viticulture, 16, 144-158.

34. Slimestad, R., Fossen, T., Brede, C. (2020). Flavonoids and other phenolics in herbs commonly used in Norwegian commercial kitchens. Food Chemistry, 309, art. no. 125678.

https://doi.org/10.1016/j.foodchem.2019.125678

35. Słowianek, M., Leszczyńska, J. (2016). Antioxidant properties of selected culinary spices. Herba Polonica, 62 (1), 29-41.

https://doi.org/10.1515/hepo-2016-0003

36. Spréa, R.M., Fernandes, Â., Calhelha, R.C., Pereira, C., Pires, T.C.S.P., Alves, M.J., Canan, C., Barros, L., Amaral, J.S., Ferreira, I.C.F.R. (2020). Chemical and bioactive characterization of the aromatic plant Levisticum officinale W.D.J. Koch: a comprehensive study. Food \& Function, 11 (2), 1292-1303.

https://doi.org/10.1039/C9FO02841B
37. Swamy, M.K., Arumugam, G., Kaur, R., Ghasemzadeh, A., Yusoff, M.M., Sinniah, U.R. (2017). GC-MS based metabolite profiling, antioxidant and antimicrobial properties of different solvent extracts of Malaysian Plectranthus amboinicus leaves. Evidence-Based Complementary and Alternative Medicine, 2017, art. no. 10 .

https://doi.org/10.1155/2017/1517683

38. Tajner-Czopek, A., Gertchen, M., Rytel, E., Kita, A., Kucharska, A.Z., Sokól-Łętowska, A. (2020). Study of antioxidant activity of some medicinal plants having high content of caffeic acid derivatives. Antioxidants, 9(5) art. no. 412.

https://doi.org/10.3390/antiox9050412

39. Tapsell, L.C., Hemphill, I., Cobiac, L., Patch, C.S., Sullivan, D.R., Fenech, M., Roodenrys, S., Keogh, J.B., Clifton, P.M., Williams, P.G., Fazio, V.A., Inge, K.E. (2006). Health benefits of herbs and spices: the past, the present, the future. The Medical Journal of Australia, 185(S4), S1-S24.

https://doi.org/10.5694/j.1326-5377.2006.tb00548.x

40. Tomsone, L., Kruma, Z., (2014). Influence of freezing and drying on the phenol content and antioxidant activity of horseradish and lovage. Conference Proceedings - Baltic Conference on Food Science and Technology "FOODBALT 2014", eISSN 2255-9817, pp. 192-197.

41. Tvrdá, E., Varga, A., Slávik, M., Árvay, J. (2019). Levisticum officinale and its effects on bovine spermatozoa activity. Journal of Microbiology, Biotechnology and Food Sciences, 8(5), 1212-1216. https://doi.org/10.15414/jmbfs.2019.8.5.1212-1216

42. Ulewicz-Magulska, B., Wesolowski, M. (2019). Total phenolic contents and antioxidant potential of herbs used for medical and culinary purposes. Plant Foods for Human Nutrition, 74, 61-67. https://doi.org/10.1007/s11130-018-0699-5

43. Wangensteen, H., Samuelsen, A.B., Malterud, K.E. (2004). Antioxidant activity in extracts from coriander. Food Chemistry, 88(2), 293-297. https://doi.org/10.1016/j.foodchem.2004.01.047

44. Yashin, A., Yashin, Y., Xia, X., Nemzer, B. (2017). Antioxidant activity of spices and their impact on human health: a review. Antioxidants, 6(3), art. no. 70.

https://doi.org/10.3390/antiox6030070

45. Zawiślak, G., Nurzyńska-Wierdak, R. (2014). Evaluation of the yield and biological value of tarragon (Artemisia dracunculus L.) in the bunch harvest cultivation. Acta Scientiarum Polonorum, Hortorum Cultus, 13(4), 185-198.

46. Złotek, U., Szymanowska, U., Pecio, Ł., Kozachok, S., Jakubczyk, A. (2019). Antioxidative and potentially anti-inflammatory activity of phenolics from lovage leaves Levisticum officinale Koch elicited with jasmonic acid and yeast extract. Molecules, 24(7), art. no. 1441. https://doi.org/10.3390/molecules24071441

47. Zujko, M.E., Witkowska, A.M., Waśkiewicz, A., Sygnowska, E. (2012). Estimation of dietary intake and patterns of polyphenol consumption in Polish adult population. Advances in Medical Sciences, 57(2), 375-384. https://doi.org/10.2478/v10039-012-0026-6 